\title{
Climate Change Threatens the World's Marine Protected Areas
}

1 John F. Bruno ${ }^{1}$, Amanda E. Bates ${ }^{2,3}$, Chris Cacciapaglia ${ }^{4}$, Elizabeth P. Pike ${ }^{5}$, Steven Amstrup ${ }^{6}$, Ruben

2 van Hooidonk ${ }^{7,8}$, Stephanie A. Henson ${ }^{9}$, and Richard B. Aronson 4

${ }^{1}$ Department of Biology, The University of North Carolina at Chapel Hill, Chapel Hill, NC 27599-3280, USA

${ }^{2}$ Ocean and Earth Science, National Oceanography Centre Southampton, University of Southampton, Southampton SO14 3ZH, UK

${ }^{4}$ Department of Biological Sciences, Florida Institute of Technology, 150 West University Boulevard, Melbourne, FL, USA 32901

${ }^{5}$ Marine Conservation Institute, Seattle, WA, USA 98103

6

${ }^{6}$ Polar Bears International, P.O. Box 3008, Bozeman, MT, USA 59772

$7 \quad{ }^{7}$ NOAA Atlantic Oceanographic and Meteorological Laboratory, Ocean Chemistry and Ecosystems

8 Division, 4301 Rickenbacker Causeway, Miami, FL 33149, USA

$9{ }^{8}$ Cooperative Institute for Marine and Atmospheric Studies, Rosenstiel School of Marine and Atmospheric 10 Science, University of Miami, 4600 Rickenbacker Causeway, Miami, FL 33149, USA sispip?

119 National Oceanography Centre, Southampton, SO14 3ZH, UK 
Marine Protected Areas (MPAs) are a primary management tool for mitigating threats to marine biodiversity ${ }^{1,2}$. MPAs and the species they protect, however, are increasingly being impacted by climate change. Here we show that, despite local protections, the warming associated with continued business-as-usual (BAU) emissions (RCP8.5) ${ }^{3}$ will likely result in further habitat and species losses throughout low-latitude and tropical MPAs ${ }^{4,5}$. With continued BAU emissions, mean sea-surface temperatures (SST) within MPAs are projected to increase $0.034{ }^{\circ} \mathrm{C} /$ year and warm an additional $2.8^{\circ} \mathrm{C}$ by 2100 . Under these conditions, the time of emergence (the year when SST and oxygen concentration exceed natural variability) for 309 no-take marine reserves, is midcentury in $42 \%$ of reserves. Moreover, projected warming rates and the existing "Community Thermal Safety Margin" (CTSM, the inherent buffer against warming based on the thermal sensitivity of constituent species) both vary among ecoregions and with latitude. The CTSM will be exceeded by 2050 in the tropics and by 2150 for many higher latitude MPAs. Importantly, the spatial distribution of emergence is stressor-specific. Hence, rearranging MPAs to minimize exposure to one stressor could well increase exposure to another. Continued BAU emissions will likely disrupt many marine ecosystems, reducing the benefits of MPAs.

Species largely restricted to marine reserves could be especially sensitive to anthropogenic climate change because of their typically small populations and low genetic diversities ${ }^{6}$. Case studies indicate that global-warming-induced climate changes already are having substantial effects on populations and ecosystems otherwise protected within terrestrial and marine reserves ${ }^{7,8}$. Gradual warming over the last several decades and unusually high seawater temperatures in early 2016 , for example, caused mass coral mortality across much of the northern Great Barrier Reef (GBR), a UNESCO World Heritage Site and model MPA ${ }^{9}$. Despite its isolation and effective protection from harvesting, pollution, and other stressors, warming radically altered the northern GBR. This and similar case studies, as well as synthetic analysis ${ }^{10}$, call into question the long-term effectiveness of MPAs in protecting their resident biotas in the face of climate change.

Anthropogenic carbon emissions lead to acute and chronic perturbations, including increasing storm intensity, rising sea levels, altered upwelling regimes, ocean acidification, and deoxygenation ${ }^{11-14}$. As a result, organisms must simultaneously adjust their physiologies to cope with multiple threats that in 
some cases could be selecting for opposing traits. We focused on two critical effects influencing MPAs: rising temperatures and changing oxygen concentrations. The oceans are absorbing over $90 \%$ of the additional heat being trapped by anthropogenic greenhouse gases, causing increases in ocean temperature even in the deep sea ${ }^{15}$. Deoxygenation, caused by warming and increasing shallow-water stratification, is predicted to affect primary production and a variety of physiological and geochemical processes ${ }^{13,16}$. Moreover, warming and deoxygenation can impact organisms synergistically because warming decreases oxygen concentration while increasing the metabolism and oxygen demand of ectotherms, e.g., fishes and invertebrates ${ }^{17}$.

We asked how much the world's MPAs can be expected to warm and lose oxygen under the business-as-usual emissions trajectory RCP 8.5 and the RCP 4.5 mitigation scenario, for which emissions peak around 2040 and $\mathrm{CO}_{2}$ concentration stabilizes at $~ 525$ ppm in 2100 (ref. 2). We used CMIP5 models to predict the mean $21^{\text {st }}$ century rate of change in SST and $\mathrm{O}_{2}$ at the geographic centers of 8236 MPAs around the world (Fig. 1A). We also assessed warming and deoxygenation rates in 309 no-take reserves (a subset of the 8236 MPAs), in which fishing is banned.

With BAU emissions, mean SSTs are predicted to increase within nearly all MPAs: the average warming rate is $0.034^{\circ} \mathrm{C} /$ year (Table 1), with a maximum increase of $0.113^{\circ} \mathrm{C} /$ year in northern Baffin Bay off northwest Greenland. This predicted future warming continues the trend of recent anthropogenic warming of $0.07^{\circ} \mathrm{C} /$ decade, on average, since $1960^{14,18}$. Projected warming rates increase slightly with latitudinal zone, from the tropics to polar oceans (Table 1). Remarkably, under RCP $8.5,99 \%$ of the world's MPAs are forecasted to warm $\geq 2^{\circ} \mathrm{C}$ by 2100 . The RCP 4.5 mitigation scenario predicts warming rates roughly $50 \%$ lower than those projected for the BAU scenario (Table 1). Under RCP 4.5, mean warming rates range from $0.014{ }^{\circ} \mathrm{C} /$ year in tropical MPAs to 0.019 in polar MPAs.

The effects of ocean warming on marine species and ecosystems, which are already welldocumented ${ }^{19-22}$, would likely increase if the rates of warming under RCP 8.5 are realized. Several recent studies have combined projected warming, species-specific thermal tolerances, and patterns of species distribution to predict changes in species richness and composition in response to ocean warming. For example, Stuart-Smith et al. ${ }^{4}$ predicted that nearly $100 \%$ of extant species will be excluded from many tropical reef communities by 2115 under RCP 8.5. Likewise, Molinos et al. ${ }^{5}$ predicted drastic declines in 
the regional species pools of tropical marine communities and substantial increases in temperate communities, accompanied by changes in species composition. These projected responses are driven by populations tracking the geographic movement of their thermal niches and shifting their ranges, generally to higher latitudes ${ }^{19,23}$. In mid- to high-latitude ecosystems, shifts in species composition will likely lead to changes in species interactions and food-web dynamics, losses of foundation species such as kelps, and invasions of new predators, competitors, and parasites ${ }^{19,24}$. In contrast, as tropical communities cross their thermal thresholds, the primary outcome is expected to be biodiversity loss, as there are no climate change induced-migrants to colonize from warmer regions. Thus, ocean warming could have fundamentally different impacts on the biota currently protected in tropical and temperate MPAs. Finally, due to temperature-dependent metabolism of fishes and invertebrates, which are ectotherms, warming will have strong, non-lethal effects on a wide array of population-, community-, and ecosystem-level processes, including developmental and dispersal rates, species interactions, and the standing biomass of plants and animals ${ }^{21,25-27}$.

Not all of these effects will be realized in every MPA. For example, individuals can acclimatize and populations can adapt to warming. However, there are limits to the scope and rate of both acclimatization and adaptation that vary with phylogenetic history, life history, and other biological attributes. Moreover, anthropogenic warming is occurring far more rapidly than natural warming has over the last 65 million years ${ }^{28}$. If emissions quickly peak and stabilize in the next few decades (RCP 4.5) how much is unclear.

Under RCP 8.5, by 2050 trends in warming and deoxygenation, as well as declining pH, all exceed background variability over $86 \%$ of the ocean ${ }^{11}$. In fact, $\mathrm{pH}$ emerged in all marine reserves decades ago (Fig. S1). Assuming organisms are adapted to local environmental conditions, this degree of change of multiple environmental variables that strongly affect their metabolism and fitness, and largely

92 define their fundamental niches, could potentially lead to local extinctions and changes in species 93 composition. We considered this emergence point-the exceedance of natural variability - to be a 94 threshold for population and community responses to climate change ${ }^{11}$. We calculated the year of 95 emergence (i.e., the timing of exceedance) of warming and deoxygenation for no-take marine reserves at 
different latitudes (Fig. 2). Under RCP 8.5, both stressors emerge by mid-century in $42 \%$ of no-take zones. Unlike deoxygenation (Fig. 2B), the year of emergence for temperature was later by decades for high-latitude reserves (Fig. 2A, but note there is substantial variation at a given latitude). By contrast, temperature has already exceeded background variability for many tropical reserves. For a number of reasons, the effect exceeding these and other environmental thresholds cannot be predicted with absolute certainty. For one, the realized environmental tolerances and adaptability for most species are unknown. However, given the effects warming in particular is already having on populations of habitatforming species such as corals ${ }^{9}$ and on the geographic ranges of countess taxa ${ }^{19}$, further change will likely exacerbate biodiversity shifts away from the tropics and towards higher latitudes.

Warming rates are projected to be relatively modest in some marine ecoregions ${ }^{29}$, including many around Australia and New Zealand, and more rapid in others, such as the Western Mediterranean and

107 South Orkney Islands (Table S1). However, the substantial variation in the inherent thermal sensitivity of 108 constituent species (i.e., thermal bias ${ }^{4}$ ) among ecoregions complicates geographic comparison of predicted warming impacts. The margin between what a species can tolerate and local maximum temperatures, averaged across all species in a community, is the "Community Thermal Safety Margin" (CTSM). Exceeding the CTSM means that maximum summertime temperatures exceed the realized maximum for the average species within the community. This could lead to the loss of a substantial number of species, even with a reasonable degree of adaptation or acclimatization ${ }^{4,5}$. Based on predicted

114 warming under RCP 8.5, for many tropical ecoregions the CTSM will be exceeded by 2050 but not until $115 \sim 2150$ at temperate latitudes (Fig. 2C).

117 regions expected to warm less or not at all, i.e., climate change refugia ${ }^{30,31}$. However, forecasted warming 118 rates for MPAs roughly match mean background rates; MPAs are warming at the same rate as 119 unprotected areas, except in polar regions (Table 2). At a smaller scale, we found that there is substantial 120 variation among ecoregions in projected warming (Table S1), but that MPA placement has not been 121 focused on ecoregions with lower rates (Fig. S2). However, even if future MPAs are better positioned in 122 regard to projected warming, the distribution of other important climate-change stressors such as 123 deoxygenation is spatially discordant with that of temperature (Fig. 3), and may also be decoupled from 
124 the inherent sensitivity of communities to these stressors. Locations for which SST emerges after 2050

125

126

127

128

129

130

131

132

133

134

135

136

137

138

139

140

141

142 are already in jeopardy. under RCP 8.5 are primarily in the Southern Ocean, whereas refugia from deoxygenation are mainly tropical (Fig. 3). Critically, only $3.5 \%$ of existing MPAs overlap with multi-variable refugia (Fig. 3). Marine biodiversity is already being degraded by numerous stressors unrelated to carbon emissions such as fishing, habitat loss, and pollution ${ }^{32}$. Populations of marine vertebrates, especially predators, have been reduced by 50 to $95 \%$ in most oceanic regions ${ }^{33-35}$, and habitat-forming species such as seagrasses, mangroves, and corals are declining by roughly $1 \%$ annually ${ }^{36-38}$. Although not a panacea, well-enforced MPAs, particularly no-take marine reserves, effectively mitigate some of these threats and partially restore marine biodiversity ${ }^{2,39}$. A recent meta-analysis found that to meet the biodiversity and fisheries goals of MPAs, global coverage needs to be increased from $4 \%$ of the world's oceans to $30 \%$ or greater ${ }^{40}$. While we support the rapid expansion of fully-protected MPAs and other forms of local conservation, our findings highlight the critical caveat that local protection is necessary but insufficient to conserve and restore marine biota ${ }^{1}$. Although MPAs are widely-promoted as a means to mitigate the effects of climate change ${ }^{41}$, the opposite perspective is more in line with the scientific reality: without drastic reductions in carbon emissions, ocean warming, acidification, and oxygen depletion in the $21^{\text {st }}$ century will in all likelihood disrupt the composition and functioning of the ecosystems currently protected within the world's MPAs. The community- and ecosystem-level impacts of climate change threaten to negate decades of progress in conservation and further imperil species and ecosystems that 
145 Supplementary Information is available in the online version of the paper.

146

147 Acknowledgements We thank Mark Ruddy for assistance with coding and data analysis, and for

148 preparing Figure 1. This research was supported by the U.S. National Science Foundation (OCE-

1491535007 to R.B.A.). This is contribution ZZZ from the Institute for Research on Global Climate Change at

150 the Florida Institute of Technology.

151

152 Author Contributions J.F.B., R.B.A., and S.C.A. conceived the study. J.F.B., A.E.B., C.C, and S.A.H.

153 performed the analysis. J.F.B. A.E.B., S.A.H. and R.B.A. interpreted the results. J.F.B., R.B.A., and

154 A.E.B. wrote the manuscript, with substantial assistance from the other authors. A.E.B., E.P.P., R.v.H., 155 and S.A.H. provided datasets.

156

157 Author Information Reprints and permissions information is available at www.nature.com/reprints. The

158 authors declare no competing financial interests. Readers are welcome to comment on the online version

159 of the paper. Publisher's note: Springer Nature remains neutral with regard to jurisdictional claims in

160 published maps and institutional affiliations. Correspondence and requests for materials should be

161 addressed to J.F.B. (jbruno@unc.edu).

162

163 Reviewer Information Nature thanks the anonymous reviewer(s) for their contribution to the peer review 164 of this work.

165

166 


\section{Literature Cited}

168 1. Allison GW, Lubchenco J, Carr MH. Marine reserves are necessary but not sufficient for marine $169 \quad$ conservation. Ecol Appl. 1998;8(sp1).

1702 2. Edgar GJ, Stuart-Smith RD, Willis TJ, et al. Global conservation outcomes depend on marine 171

4. Stuart-Smith RD, Edgar GJ, Barrett NS, Kininmonth SJ, Bates AE. Thermal biases and protected areas with five key features. Nature. 2014;506(7487):216-220. doi:10.1038/nature13022

3. van Vuuren DP, Edmonds J, Kainuma M, et al. The representative concentration pathways: an overview. Clim Change. 2011;109(1-2):5-31. doi:10.1007/s10584-011-0148-z

5. García Molinos J, Halpern BS, Schoeman DS, et al. Climate velocity and the future global

6. Peters RL. The Greenhouse Effect and Nature Reserves. Bioscience. 1985;35(11):707-717. doi:10.2307/1310052

7. Graham N a J, McClanahan TR, MacNeil MA, et al. Climate warming, marine protected areas and the ocean-scale integrity of coral reef ecosystems. PLoS One. 2008;3(8):e3039. doi:10.1371/journal.pone.0003039

8. Monahan WB, Fisichelli NA. Climate exposure of US national parks in a new era of change. PLoS One. 2014;9(7):e101302.

9. Hughes TP, Kerry J, Álvarez-Noriega M, et al. Global warming and recurrent mass bleaching of corals. Nature. 2017. doi:10.1038/nature21707

10. Selig ER, Casey KS, Bruno JF. Temperature-driven coral decline: the role of marine protected areas. Glob Chang Biol. 2012;18(5):1561-1570. doi:10.1111/j.1365-2486.2012.02658.x

11. Henson SA, Beaulieu C, llyina T, et al. Rapid emergence of climate change in environmental drivers of marine ecosystems. Nat Commun. 2017;8(5020):14682. doi:10.1038/ncomms14682

12. Gattuso J-P, Magnan A, Bille R, et al. Contrasting futures for ocean and society from different anthropogenic CO2 emissions scenarios. Science (80- ). 2015;349(6243):aac4722-1-aac4722-10. 
doi:10.1126/science.aac4722

13. Breitburg D, Levin LA, Oschlies A, et al. Declining oxygen in the global ocean and coastal waters. Science (80- ). 2018;359(January):eaam7240. doi:10.1126/science.aam7240

14. Burrows MT, Schoeman DS, Buckley LB, et al. The Pace of Shifting Climate in Marine and Terrestrial Ecosystems. Science (80- ). 2011;334(6056):652-655. doi:10.1126/science.1210288

15. Gleckler PJ, Durack PJ, Stouffer RJ, Johnson GC, Forest CE. Industrial-era global ocean heat uptake doubles in recent decades. Nat Clim Chang. 2016;6(4):394-398. http://dx.doi.org/10.1038/nclimate2915.

16. Keeling RF, Arne K, Gruber N. Ocean deoxygenation in a warming world. Annu Rev Mar Sci. 2010;2:199-229. doi:10.1146/annurev.marine.010908.163855

17. Pörtner H, Bock C, Mark FC. Oxygen- and capacity-limited thermal tolerance: bridging ecology and physiology. J Exp Biol. 2017;220:2685-2696. doi:10.1242/jeb.134585

18. Chollett I, Müller-Karger FE, Heron SF, Skirving W, Mumby PJ. Seasonal and spatial heterogeneity of recent sea surface temperature trends in the Caribbean Sea and southeast Gulf of Mexico. Mar Pollut Bull. March 2012. doi:10.1016/j.marpolbul.2012.02.016

19. Poloczanska ES, Brown CJ, Sydeman WJ, et al. Global imprint of climate change on marine life. Nat Clim Chang. 2013;3(10):919-925. doi:10.1038/nclimate1958

20. Wernberg T, Bennett S, Babcock RC, et al. Climate-driven regime shift of a temperate marine ecosystem. Science (80- ). 2016;353(6295):169. doi:10.1126/science.aad8745

21. Kordas RL, Harley CDG, O'Connor MI. Community ecology in a warming world: The influence of temperature on interspecific interactions in marine systems. J Exp Mar Bio Ecol. 2011;400(12):218-226. doi:10.1016/j.jembe.2011.02.029

22. Harley CDG, Randall Hughes a, Hultgren KM, et al. The impacts of climate change in coastal marine systems. Ecol Lett. 2006;9(2):228-241. doi:10.1111/j.1461-0248.2005.00871.x

23. Pinsky ML, Worm B, Fogarty MJ, Sarmiento JL, Levin SA. Marine taxa track local climate velocities. Science (80- ). 2013;341(6151):1239-1242. doi:10.1126/science.1239352

24. Aronson RB, Thatje S, Clarke A, et al. Climate change and invasibility of the Antarctic benthos. Annu Rev Ecol Evol Syst. 2007;38(1):129-154. doi:10.1146/annurev.ecolsys.38.091206.095525 
25. Bruno JF, Carr LA, O'Connor MI. Exploring the role of temperature in the ocean through metabolic scaling. Ecology. 2015;96(12):3126-3140. doi:10.1890/14-1954.1

26. Svensson F, Karlsson E, Gårdmark A, et al. In situ warming strengthens trophic cascades in a coastal food web. Oikos. 2017:In press.

27. O'Connor MI, Piehler MF, Leech DM, Anton A, Bruno JF. Warming and resource availability shift food web structure and metabolism. PLoS Biol. 2009;7(8):e1000178. doi:10.1371/journal.pbio.1000178

28. Diffenbaugh NS, Field CB. Changes in ecologically critical terrestrial climate conditions. Science (80- ). 2013;341(6145):486. doi:10.1126/science.1237123

29. Spalding MD, Fox HE, Allen GR, et al. Marine ecoregions of the world: A bioregionalization of coastal and shelf areas. Bioscience. 2007;57(7):573-583. doi:10.1641/B570707

30. Cacciapaglia C, van Woesik R. Reef-coral refugia in a rapidly changing ocean. Glob Chang Biol. 2015;21(6):2272-2282. doi:10.1111/gcb.12851

31. McLeod E, Salm R, Green A, Almany J. Designing marine protected area networks to address the impacts of climate change. Front Ecol Environ. 2009;7(7):362-370. doi:10.1890/070211

32. Jackson JBC, Kirby MX, Berger WH, et al. Historical overfishing and the recent collapse of coastal ecosystems. 2001;293(July):629-638.

33. McCauley DJ, Pinsky ML, Palumbi SR, Estes J a., Joyce FH, Warner RR. Marine defaunation: Animal loss in the global ocean. Science (80- ). 2015;347:247-254. doi:10.1126/science.1255641

34. Valdivia A, Cox CE, Bruno JF. Predatory fish depletion and recovery potential on Caribbean reefs. 2017;(iii):1-12. doi:10.1126/sciadv.1601303

35. Myers RA, Worm B. Rapid worldwide depletion of predatory fish communities. 2003;423(May):280-283.

36. Waycott M, Duarte CM, Carruthers TJB, et al. Accelerating loss of seagrasses across the globe threatens coastal ecosystems. Proc Natl Acad Sci. 2009;106:12377-12381. doi:10.1073/pnas.0905620106

37. Polidoro BA, Carpenter KE, Collins L, et al. The loss of species: Mangrove extinction risk and geographic areas of global concern. Hansen DM, ed. PLoS One. 2010;5(4):e10095. 
252 38. Bruno JF, Selig ER. Regional decline of coral cover in the Indo-Pacific: timing, extent, and $253 \quad$ subregional comparisons. PLoS One. 2007:e711.

254 39. Lester SE, Halpern BS, Grorud-Colvert K, et al. Biological effects within no-take marine reserves: A global synthesis. Mar Ecol Prog Ser. 2009;384:33-46. doi:10.3354/meps08029

40. O'Leary BC, Winther-Janson M, Bainbridge JM, Aitken J, Hawkins JP, Roberts CM. Effective coverage targets for ocean protection. Conserv Lett. 2016;9(6):398-404. doi:10.1111/conl.12247

258 41. Roberts CM, O'Leary BC, McCauley DJ, et al. Marine reserves can mitigate and promote adaptation to climate change. Proc Natl Acad Sci . 2017;114(24):6167-6175. 
264 Projected temperature values: Sea Surface Temperature (SST) data were obtained from CMIP5 climate 265 ensembles for both RCP 4.5 and RCP 8.5 at a spatial resolution of $1 \times 1^{\circ}$ (archived by the Earth System 266 Grid Federation at: http://pcmdi9.Ilnl.gov and in the papers GitHub repository:

267 https://github.com/johnfbruno/MPAs warming. Cell-specific warming rates for the climate scenarios 268 (RCP 4.5 and RCP 8.5) were calculated as linear rates of change $\left({ }^{\circ} \mathrm{C} /\right.$ year) for both the annual mean and 269 annual maximum SST, between 2006 (based on observed current temperatures) and predicted 2100 270 temperatures. These data were saved as raster files and imported into R Studio ${ }^{42}$ using the R package 271 raster $^{43}$. We also examined predicted values from a downscaled model $(<5 \mathrm{~km}$ scale) from van Hooidonk

272 et al. ${ }^{44}$. The downscaling was achieved by adjusting both the annual cycle and mean temperature with 273 observed data from the Pathfinder 5.0 climatology 44 . The $1 \times 1^{\circ}$ data ranged from $90^{\circ} \mathrm{N}$ to $90^{\circ} \mathrm{S}$ whereas 274 the downscaled data ranged from $45^{\circ} \mathrm{N}$ to $45^{\circ} \mathrm{S}$. Because of the geographic restriction of the downscaled 275 data, it was used only to validate the use of $1 \times 1^{\circ}$ resolution data for the global analysis. This was done by comparing projections between the two datasets within the overlapping geographic extent and testing for bias along a latitudinal gradient (Table S2, Figs. S3 \& S4). Although projections are very similar, there is 278 minor bias across latitudes between the native and downscaled models: the downscaling procedure 279 produces projections that favor faster warming in the southern hemisphere, while the native $1 \times 1$ models 280 favor faster warming in the northern hemisphere (between $45^{\circ} \mathrm{N}$ and $45^{\circ} \mathrm{S}$ ).

MPA locations: Coordinates and information for Marine Protected Areas (MPAs) in the world's oceans were provided by the Marine Conservation Institute, based on a database provided by the UNEP-WCMC and IUCN:

Marine Conservation Institute. (2016). MPAtlas. Seattle, WA. www.mpatlas.org [Accessed Sept 2016] - based on data provided by UNEP-WCMC and IUCN. (WDPA) [On-line], Cambridge, UK: UNEP-WCMC and IUCN. Available at: www.protectedplanet.net. 
These coordinates (the centroids of each MPA) are available in the papers GitHub repository: https://github.com/johnfbruno/MPAs warming.

Climatic data were extracted from the raster cell closest to the centroid of the spatial polygon for each MPA, and the distance between the raster value and centroid was measured. A downscaled SST raster from Bio-ORACLE ${ }^{45}$ was used as a land mask for the CMIP5 ensemble data to filter out unwanted MPA coordinates. To prevent the analysis from including both freshwater MPAs, such as ones in the Great Lakes, and MPAs with incorrectly labelled coordinates, extracted cells greater than $50 \mathrm{~km}$ away from the MPA centroid were removed from the analysis. The extracted temperature data were then stratified into four groups: 1) polar, ranging from $66.5^{\circ}$ to $90^{\circ}$ latitude $\left.(n=166) ; 2\right)$ temperate, ranging from $40^{\circ}$ to $66.5^{\circ}$ latitude ( $n=2738)$; 3 ) subtropical, ranging from $23.5^{\circ}$ to $40^{\circ}$ latitude $(n=2738)$; and tropical ranging from $23.5^{\circ} \mathrm{S}$ to $23.5^{\circ} \mathrm{N}$ across the equator $(\mathrm{n}=2458)$. All data and $\mathrm{R}$ code used to summarize MPA warming trends (e.g., at different latitudes) is archived at GitHub: https://github.com/johnfbruno/MPAs warming.

Time of Emergence (TOE) calculations: The ToE estimates are taken from Henson et al. (2017); a summary of the approach is given here. ToE is calculated for the annual maxima of SST and the annual minima of thermocline average oxygen concentration. Trends in SST and oxygen are calculated using a generalized least squares model with a first-order autoregressive error term. The time series of annual extrema in the conjoined historical and warming scenario (RCP8.5) runs is created. An inflection point is then identified by calculating the cumulative sum of the gradient in the time series and finding the year when it exceeds zero (for a negative trend) or drops below zero (for a positive trend) for the remainder of

312 the time series. The trend in the time series is then calculated from the inflection point forward to 2100.

313 The natural variability (i.e. noise) is defined using a 100-year section of the model's control run as one 314 standard deviation in the annual extrema time series. The time of emergence is then defined as:

$$
\text { ToE }=(2 . \text { noise }) / \text { trend }
$$

317 Any values of ToE that exceed 2100 are excluded from the analysis. 
Community Thermal Safety Margin (CTSM) analysis: We use the mean thermal bias ${ }^{46}$ (TBiasmax) for 34 marine ecoregions, as reported in the Extended Data Table S1. In brief, for each of these ecoregions "TBiasmax" was calculated as an average across communities sampled within the ecoregion. TBiasmax integrates the average upper temperature occupied across all species in a community with the local temperature to quantify a warming buffer (which we call the "Community Thermal Safety Margin", CTSM)

- we use this term because this metric is essentially the community-weighted mean for the species thermal safety margin (TSM): the 95th percentile of species' thermal distributions - a measure of realized upper thermal limits across repeated surveys of fish and mobile invertebrates (Reef Life Survey, $\underline{\text { http://reeflifesurvey.com }}{ }^{47}$ ) minus the mean summer temperatures (quantified for the years ranging between 2008 and 2014) for a particular location in which a species is observed, as described in StuartSmith et al. ${ }^{46}$ (where mean SST from the eight warmest weeks of each year ${ }^{48}$ ).

Data availability: Data generated during the study are available in public repositories including within the study's GitHub repository.

\section{Literature Cited for the Methods}

335

42. R Core Team (2015). R: A language and environment for statistical computing. R Foundation for

43. Hijmans, RJ (2015). raster: Geographic Data Analysis and Modeling. R package version 2.4-20. http://CRAN.R-project.org/package=raster

44. van Hooidonk RJ, Maynard J, Tamelander J et al. (2016) Local-scale projections of coral reef vulnerability to warming in the world's marine fauna. Nature 528(7580), 88-92. 
346 47. Edgar, GJ, Stuart-Smith, RD (2014) Systematic global assessment of reef fish communities by the Reef Life Survey program. Scientific Data 1, 140007.

348 48. Reynolds, R. W. et al. (2007) Daily high-resolution-blended analyses for sea surface temperature.

349 Journal of Climate 20, 5473-5496.

350

351 
352 Table 1. Projected rates of increase of ocean temperature (mean SST ${ }^{\circ} \mathrm{C} /$ year $\pm 1 \mathrm{SD}=$ the $\mathrm{SD}$ of 353 estimates of warming rates across MPAs) in no-take marine reserves and for MPAs in four latitudinal 354 zones for two different emission scenarios (RCP 8.5 and 4.5) based on CMIP5 simulation ensembles 355 (2006-2100). Mean values are the means annual changes in the mean temperature across units (e.g., no356 take reserves or all MPAs). Maximum values are the means of the maximum projected values across all 357 units.

\begin{tabular}{lccccccc}
\hline Metric & Scenario & $\begin{array}{c}\text { Reserves } \\
\mathbf{( 3 0 9 )}\end{array}$ & $\begin{array}{c}\text { All MPAs } \\
\mathbf{( 8 2 3 6 )}\end{array}$ & $\begin{array}{c}\text { Tropical } \\
\mathbf{( 2 4 5 8 )}\end{array}$ & $\begin{array}{c}\text { Subropical } \\
\mathbf{( 2 7 3 8 )}\end{array}$ & $\begin{array}{c}\text { Temperate } \\
\mathbf{( 2 7 3 8 )}\end{array}$ & $\begin{array}{c}\text { Polar } \\
\mathbf{( 1 6 6 )}\end{array}$ \\
\hline Mean & RCP 8.5 & $0.033 \pm 0.004$ & $0.034 \pm 0.006$ & $0.032 \pm 0.002$ & $0.034 \pm 0.004$ & $0.036 \pm 0.007$ & $0.038 \pm 0.013$ \\
Mean & RCP 4.5 & $0.014 \pm 0.002$ & $0.015 \pm 0.003$ & $0.014 \pm 0.001$ & $0.015 \pm 0.002$ & $0.016 \pm 0.004$ & $0.019 \pm 0.009$ \\
Max & RCP 8.5 & $0.035 \pm 0.006$ & $0.037 \pm 0.007$ & $0.033 \pm 0.002$ & $0.037 \pm 0.006$ & $0.042 \pm 0.007$ & $0.043 \pm 0.011$ \\
Max & RCP 4.5 & $0.015 \pm 0.003$ & $0.016 \pm 0.003$ & $0.014 \pm 0.001$ & $0.016 \pm 0.003$ & $0.018 \pm 0.004$ & $0.021 \pm 0.004$ \\
\hline
\end{tabular}


361 Table 2 Projected rates of increase (mean values of change in ${ }^{\circ} \mathrm{C} /$ year and number of grid cells) of 362 ocean temperatures in MPAs and for entire latitudinal zones (all 1x1 degree cells) for RCP 8.5. Overall 363 mean rate of the global ocean is $0.0333\left({ }^{\circ} \mathrm{C} /\right.$ year, $\mathrm{N}=43,268$ cells). Zone-specific values were based on 364 cell area weighted means.

\begin{tabular}{lcccc}
\hline & Tropical & Subropical & Temperate & Polar \\
\hline MPAs only & $0.032(2458)$ & $0.034(2738)$ & $0.036(2738)$ & $0.038(166)$ \\
Zone & $0.032(13227)$ & $0.031(9233)$ & $0.032(13940)$ & $0.065(6868)$ \\
\hline
\end{tabular}

365

366 
Figure 1. Patterns of projected ocean warming. Annual warming rates $\left({ }^{\circ} \mathrm{C} /\right.$ year $)$ are based on CMIP5 simulation ensembles under the RCP 8.5 emissions scenario, 2006-2100. Black dots are MPAs used in

371 the study.

Figure 2. Latitudinal patterns of the year that environmental conditions will exceed predicted thresholds. For a \& b: Red circles are fully protected reserves in which thresholds have already been exceeded (in 2017), blue circles are reserves that have not, and grey circles are grid cells not in a marine reserve. Black lines are fitted functions from a GAM that includes a spatial autocorrelation term. c: The year that the Community Thermal Safety Margins (CTSM) will be exceeded for marine ecoregions (blue circles) based on the predicted mean warming rate (RCP 8.5) for all MPAs in each ecoregion (see values

379 in Table S1). The CTSM is the average maximum temperature across the geographical ranges

380 (determined with 2,447 in situ surveys by the Reef Life Survey program ${ }^{4}$ ) of all species in a community 381 minus the present maximum summertime SST; it is an estimate of how far on average community 382 inhabitants are from their thermal maxima ${ }^{4}$. Note that the latitudinal extents differ in the top and bottom 383 panels due to a lack of data at high latitudes in the RLS data. The geographic pattern for CTSM emergence $(c)$ is largely driven by the inherent differences among latitudes in the CTSM ${ }^{4}(d$, plotted as

$385{ }^{\circ} \mathrm{C}$ ), which is substantially greater for higher latitude ecoregions.

Figure 3. Spatial distribution of temporary refugia from climate change and current coverage of

388 Marine Protected Areas. Areas of the ocean for which SST (orange), oxygen concentration (lilac), and both variables (red) emerge after 2050 for RCP 8.5 (top panel) and 4.5 (bottom panel). MPAs are outlined in black. 